\title{
Bacteriuria and their Antibiotic Susceptibility Patterns among People Living with HIV Attending Tikur Anbessa Specialized and Zewditu Memorial Hospital ART Clinics, Addis Ababa, Ethiopia
}

\author{
Genet Molla Fenta ${ }^{1}$, Melese Hailu Legese ${ }^{2^{*}}$ and Gebru Mulugeta Weldearegay ${ }^{2}$ \\ ${ }^{1}$ Department of Medical Laboratory Sciences, College of Medicine \& Health Sciences; Wollo University, Ethiopia \\ ${ }^{2}$ Department of Clinical Laboratory Science, School of Allied Health Sciences, College of Health Science, Addis Ababa University, Ethiopia
}

*Corresponding author: Melese Hailu Legese, Department of Clinical Laboratory Science, School of Allied Health Sciences, College of Health Science, Addis Ababa University, Ethiopia, E-mail: melerose85@gmail.com

Received date: Sept 15, 2016; Accepted date: Oct 27, 2016; Published date: Oct 31, 2016

Copyright: $\odot 2016$ Fenta GM, et al. This is an open-access article distributed under the terms of the Creative Commons Attribution License, which permits unrestricted use, distribution, and reproduction in any medium, provided the original author and source are credited.

\begin{abstract}
Background: Urinary tract infections are major causes of morbidity in people living with HIV. Hence the study aimed to determine the prevalence of bacteriuria and their antibiotic susceptibility patterns among people living with HIV.

Method: A prospective cross-sectional study conducted from April to June 2015. A total of 297 and153 participants were from Zewditu Memorial Hospital and Tikur Anbessa Specialized Hospital, respectively. First morning urine samples were collected and cultured on Blood and MacConkey agar. Culture positives were characterized by Gram stain and standard biochemical tests and Kirby-Bauer method was used for antimicrobial susceptibility patterns of the isolates. Chi-square test was used to see the relation between dependent variables and independent variables. P-value $<0.05$ were taken as statistically significance. Data was entered and analyzed using SPSS version 20.
\end{abstract}

Result: Overall prevalence of bacteriuria was $11.3 \%(n=51 / 450)$. Isolated bacteria from HAART naïve and on HAART participants were $7 \%(n=9 / 131)$ and $13 \%(n=42 / 319)$ respectively. E. coli $25(49 \%)$, S. aureus $10(19.6 \%)$ and Enterococcus species $7(13.7 \%)$ were the predominant isolated bacteria. The highest proportion of bacteria were isolated from patients having a CD4 count of less than $500 \mathrm{cells} / \mathrm{mm}^{3}(22.5 \% ; \mathrm{n}=38 / 169)$. Most bacterial isolates were sensitive to amikacin $(100 \%)$, ceftriaxone $(96 \%)$; resistant to ampicillin $(81 \%)$, sulfamethoxazole-trimethoprim $(71 \%)$ and amoxicillin-clavulanic acid $(61 \%)$. Multiple drug resistance was $78.4 \%(n=40 / 51)$. Gram positives and gram negatives accounts $65 \%(n=13 / 20)$ and $87 \%(n=27 / 31)$ of multiple drug resistance level respectively.

Conclusion: HAART users with low CD4 counts were more frequently infected with urinary pathogens compared with HAART naïve who had higher CD4 counts. More than three quarters of all isolated bacteria were resistant to two or more commonly prescribed antimicrobial drugs. Thus, regular monitoring of bacteriuria and their antimicrobial susceptibility patterns among this group of individuals is recommended to provide effective therapy and thereby prevent renal complications.

\section{Keywords: UTI; HIV; CD4; HAART; MDR; Ethiopia}

\section{Introduction}

Urinary tract infection (UTI) refers to the presence of microbial pathogens within the urinary tract and is usually classified by the site of infection: bladder [cystitis], kidney [pyelonephritis], UTI always requires the presence of bacteria in the urine (bacteriuria), but can be both asymptomatic or symptomatic, and is characterized by a wide spectrum of symptoms ranging from mild irritative voiding to bacteremia, sepsis, or even death [1]. HIV infection is associated with a variety of renal syndromes; patients with low $\mathrm{CD} 4$ counts are at risk of the neurological complications of: hyperreflexia and hyporeflexia which can lead to urinary stasis and ultimately infection [2].

Urinary tract infections accounts for a significant proportion of patients daily hospital visits in HIV patients. Untreated UTIs account for $7-60 \%$ of opportunistic infections and could be a source for ascending urinary tract infection and septicemia in immunocompromised hosts [3]. UTIs start when tiny organisms, usually bacteria from the digestive tract, cling to the opening of the urethra and begin to multiply. More than $90 \%$ of UTIs are due to enteric Gram positive and Gram negative bacteria including Escherichia coli, Proteus mirabilis, Klebsiella pneumonia, Pseudomonas aeruginosa and Staphylococcus aureus [4].

Bacterial UTIs are more common in HIV positive individuals than HIV-negative people, although the difference is driven in large part by those HIV-positive patients with CD4 counts less than 500 cells $/ \mathrm{mm}^{3}$ $[5,6]$. Symptoms and signs of UTI vary depending on sex, age, immune status, and the area of the urinary tract that is infected; some unique symptoms develop depending on the infecting agent. Females have a higher risk for UTIs than most males, probably because of their anatomy; other risk factors for UTIs include any condition that may impede urine flow (e.g., enlarged prostate, congenital urinary tract abnormalities, and inflammation) [7]. 
Citation: Fenta GM, Legese MH, Weldearegay GM (2016) Bacteriuria and their Antibiotic Susceptibility Patterns among People Living with HIV Attending Tikur Anbessa Specialized and Zewditu Memorial Hospital ART Clinics, Addis Ababa, Ethiopia. J Bacteriol Parasitol 7: 292. doi:10.4172/2155-9597.1000292

Page 2 of 7

The emergence of antibiotic resistance in the management of urinary tract infections is a serious public health problem in the globe, particularly in the developing world [8]. Antimicrobial treatment of UTIs in HIV patients is necessary; both to alleviate symptoms and to reduce the risk of renal complications like HIV associated nephropathy, pyelonephritis and acute and chronic kidney diseases [9]. Since bacterial pathogens of UTIs are variable regionally, infection control and treatment depends on knowledge of common causative organisms and their antibiotic resistance level in local scenario [10]. In Ethiopia very limited data are available regarding UTIs in the HIV positive population. Therefore we conducted a study providing information on the prevalence of bacteriuria and their antibiotic susceptibility patterns among people living with HIV.

\section{Materials and Methods}

\section{Study area, design and population}

A prospective cross-sectional study was conducted at Tikur Anbessa specialized Hospital and Zewditu Memorial hospital from April to June 2015 in Addis Ababa, Ethiopia.

\section{Eligibility criteria's}

All HIV patients who were HAART and non-HAART users attending ART clinics; gave blood for CD4 counts and urine for culture and the absence and presence of UTIs symptoms recruited based on physician decision were included. Whereas, patients who were on antibiotic therapy for two weeks prior to data collection, those under 18 years old and those who didn't gave consent were excluded.

\section{Sample size and sampling technique}

We estimated a total of 450 study participants for a $10 \%$ nonresponse rate, 297 from Zewditu Memorial Hospital and 153 from Tikur Anbessa Specialized Hospital, were recruited using convenient sampling technique. The sample size was calculated based on single population proportion sample size estimation at $95 \%$ confidence interval with $+/-5 \%$ tolerable errors using a previous study conducted in Ethiopia [11].

\section{Sample collection and processing}

From eligible participants data on socio-demographic characteristics and other associated variables were collected using a structured, pretested questionnaire. Five milliliter mid-stream urine specimens were collected from every study participants using a sterile wide mouth container. The study participants were given appropriate sample collection instructions before providing urine samples. All urine specimens were brought to microbiology laboratory within one hour of collection for culture and drug susceptibility testing. Also CD4 counts of these patients were done using BD-FACS Count.

\section{Culture and antimicrobial susceptibility pattern}

Using a sterile calibrated wire loop $(0.001 \mathrm{ml})$, all urine samples were inoculated on blood and MacConkey agar plates (Oxoid, England) and were incubated at $37^{\circ} \mathrm{C}$ for $24 \mathrm{~h}$. The number of colonies and number of different colony morphologies were counted; allowing estimation of colony-forming units (CFU) per $\mathrm{ml}$ of urine, $\geq 10^{5}$ $\mathrm{CFU} / \mathrm{ml}$ of urine was considered as significant bacteriuria. Positive cultures were characterized by colony characteristics, Gram stain and standard biochemical tests following standard operating procedures [12]. For the identification of $S$. aureus Mannitol salt agar (Oxoid, England) and DNAse agar (Oxoid, England) were used.

\section{Drug susceptibility testing}

The disk diffusion was performed and after 16-18 h of incubation at $37^{\circ} \mathrm{C}$ zone of inhibition was measured and interpreted as recommended by the Clinical and Laboratory Standards Institute (CLSI). Using a sterile wire loop, 3-5 pure colonies were picked from blood agar for Gram positives and MacConkey agar for Gram negatives and emulsified in nutrient broth. Standard inoculums adjusted to 0.5 McFarland using McFarland Densitometer was swabbed onto Muller-Hinton agar (dispensed on $100 \mathrm{~mm}$ plate). Accordingly the CLSI guideline for each category of bacteria, drug susceptibility testing was performed against penicillin G (10 unit Oxoid), ampicillin (10 $\mu \mathrm{g}$ Oxoid), amoxicillin-clavulanic acid (20/10 $\mu \mathrm{g}$ Oxoid), ceftazidime (30 $\mu \mathrm{g}$, Oxoid), ceftriaxone (30 $\mu \mathrm{g}$, Oxoid), gentamicin $(10 \mu \mathrm{g}$, Oxoid), nitrofurantoin $(300 \mu \mathrm{g}$, Oxoid), cefotaxime (30 $\mu \mathrm{g}$, Oxoid), sulfamethoxazole-trimethoprim (1.25/23.75 $\mu \mathrm{g}$, Oxoid), ciprofloxacin (5 $\mu \mathrm{g}$, Oxoid), tobramycin (10 $\mu \mathrm{g}$, Oxoid), Vancomycin $(30 \mu \mathrm{g}$, Oxoid), novobiocin $(5 \mu \mathrm{g}$, Oxoid), cefoxitin (30 $\mu \mathrm{g}$, Oxoid). Sulfamethoxazole (Oxoid, England) and Tellurite disk (Oxoid, England) were used for identification of Enterococcus species [13]. Availability and frequency of prescriptions were given attention to select those antibiotics used for the management of bacterial infections in Ethiopia keeping the CLSI guidelines. In this study multidrug resistance was defined as simultaneous resistance to two or more classes of antimicrobial agents.

\section{Quality control (QC)}

Standard Operating Procedures (SOP) were strictly followed verifying that media meet expiration date and quality control parameters per CLSI. Visual inspections of cracks in media or plastic petridishes, unequal fill, hemolysis, evidence of freezing, bubbles, and contamination was done. Quality control was performed to check the quality of medium. Each new lot was quality controlled before use by testing the Escherichia coli ATCC 25922 and/or Staphylococcus aureus ATCC25923 standard control strains.

\section{Data analysis and interpretation}

The data was analyzed using SPSS version 20. The descriptive statistics (mean, percentages or frequency) was calculated. The bivariant logistic regression analysis was used to see the relation between dependent variable and independent variables. Variables that showed a significant association were selected for further analysis using multiple logistic regression models with a $\mathrm{p}$-value $<0.05$ considered statistically significant.

\section{Data quality assurance}

Socio-demographic characteristics of patients were collected using structured data collection sheets after getting informed consent. Urine specimens were collected in accordance with SOPs and brought to bacteriology laboratory immediately for bacteriological analysis. Culture results were recorded carefully before data entry and the data was double checked by a different person before analysis. 
Citation: Fenta GM, Legese MH, Weldearegay GM (2016) Bacteriuria and their Antibiotic Susceptibility Patterns among People Living with HIV Attending Tikur Anbessa Specialized and Zewditu Memorial Hospital ART Clinics, Addis Ababa, Ethiopia. J Bacteriol Parasitol 7: 292. doi:10.4172/2155-9597.1000292

Page 3 of 7

\section{Ethical consideration}

The study was approved by "Department Research and Ethical Review Committee (DRERC)" of the Department of Medical Laboratory Science (MLS/483/16), School of Allied Health Sciences, College of Health Sciences, Addis Ababa University. Written permission letter was also obtained from the study site. The purpose and procedures of the study was explained to the study participants within the study period. Those participants who gave informed consent were selected and enrolled as the participants of the study. A patient result was communicated to the attending physicians.

\section{Results}

A total of four hundred fifty urine samples were collected from HIV patients attending Tikur Anbessa Specialized Hospital $(\mathrm{n}=153)$ and Zewditu Memorial Hospital $(\mathrm{n}=297)$ ART Clinics. Of these, $71 \%$ $(n=319 / 450)$ and $29 \%(n=131 / 450)$ were HAART and HAART naïve participants respectively. Two thirds; $68.7 \% \quad(n=309 / 450)$ of the participants were females. Among the total participants $12 \%$ $(\mathrm{n}=52 / 450)$ had symptoms of UTI.

The overall prevalence of UTI was $11.3 \%(n=51 / 450)$ distributed equally on males and females though the prevalence of UTI among males $7 \%(n=10 / 141)$ was lower than females $13 \%(n=41 / 309)$. In relation to symptoms bacteriuria was detected from $7 \%(n=29 / 398)$ of asymptomatic participants. On the other hand bacteriuria was confirmed from $42 \%(n=22 / 52)$ of participants with symptom for UTI.

The prevalence of UTI among participants on HAART and HAART naïve was $13 \%(n=42 / 319)$ and $7 \%(n=9 / 131)$ respectively. Based on CD4 count of the patients, the highest proportion of bacteria were isolated from patients having a CD4 count of less than $300 \mathrm{~mm} \mathrm{350 \%}$ $(n=9 / 18)$ followed by $300-500 \mathrm{~mm} 319 \%(n=29 / 151)$ and greater than $500 \mathrm{~mm} \mathrm{35 \%}(\mathrm{n}=13 / 281)$. There was an association between level of CD4 count and bacterial UTI $(\mathrm{P}=0.001)$ (Table 1$)$.

\begin{tabular}{|c|c|c|c|c|}
\hline Variables & Bacteriuria Positive No. (\%) & Bacteriuria Negative No. (\%) & Total No. (\%) & P-value \\
\hline \multicolumn{5}{|l|}{ Sex } \\
\hline Female & $41(13)$ & $268(87)$ & $309(69)$ & \\
\hline Male & $10(7)$ & $131(93)$ & $141(31)$ & 0.036 \\
\hline \multicolumn{5}{|l|}{ Age } \\
\hline $18-26$ & $1(5)$ & $20(95)$ & $21(5)$ & \\
\hline $27-36$ & $21(14)$ & $133(86)$ & $154(34)$ & \\
\hline $37-46$ & $20(11)$ & $166(89)$ & $186(42)$ & 0.526 \\
\hline $47-56$ & $9(12)$ & $69(88)$ & $78(17)$ & \\
\hline $57-66$ & $0(0)$ & $11(100)$ & $11(2)$ & \\
\hline \multicolumn{5}{|c|}{ CD4 Count $/ \mathrm{mm}^{3}$} \\
\hline$<300$ & $9(50)$ & $9(50)$ & $18(4)$ & \\
\hline $300-500$ & $29(19)$ & $122(81)$ & $151(34)$ & \\
\hline$>500$ & $13(5)$ & $268(95)$ & $281(62)$ & 0.001 \\
\hline \multicolumn{5}{|l|}{ HAART } \\
\hline Yes & $42(13)$ & $277(87)$ & $319(71)$ & \\
\hline No & $9(7)$ & $122(93)$ & $131(29)$ & 0.071 \\
\hline \multicolumn{5}{|c|}{ UTI symptoms } \\
\hline Yes & $22(42)$ & $30(58)$ & $52(12)$ & \\
\hline No & $29(7)$ & $369(93)$ & $398(88)$ & 0.029 \\
\hline
\end{tabular}

Table 1: Prevalence of bacterial UTI among people living with HIV

Majority of isolated bacteria were Gram negative $60.8 \%(\mathrm{n}=31 / 51)$. Escherichia coli $49 \% \quad(\mathrm{n}=25 / 51)$, Staphylococcus aureus $19.6 \%$ $(\mathrm{n}=10 / 51)$ and Enterococcus species $13.7 \%(\mathrm{n}=7 / 51)$ were the most frequent isolates whereas Staphylococcus saprophyticus 3 (5.9\%), Citrobactor 2 (3.9\%), Serratia 1 (1.9\%) and Acinetobactor 1 (1.9\%) species were the least frequent isolates from cultures of all study participants (Figure 1).
Gram negative isolates were $100 \%$ sensitive to amikacin and nitrofurantoin while they showed high rate of resistance to ampicillin (81\%) and sulfamethoxazole-trimethoprim (71\%) (Table 2). Similarly most Gram positive isolates were $100 \%$ sensitive to nitrofurantoin however they were $100 \%$ cresistant to penicillin and ampicillin (Table 3). 
Citation: Fenta GM, Legese MH, Weldearegay GM (2016) Bacteriuria and their Antibiotic Susceptibility Patterns among People Living with HIV Attending Tikur Anbessa Specialized and Zewditu Memorial Hospital ART Clinics, Addis Ababa, Ethiopia. J Bacteriol Parasitol 7: 292. doi:10.4172/2155-9597.1000292

Page 4 of 7

Most frequent isolates; E. coli were $84 \%$ sensitive to cefotaxime, ceftriaxone and ceftazidime but it showed $76 \%$ of resistance to sulfamethoxazole-trimethoprim. All isolated $S$. aureus were $90 \%$ sensitive to amoxicillin-clavulanic acid, gentamicin and cefoxitin however they were $100 \%$ resistance to ampicillin and penicillin. All isolated Enterococcus species were 100\% sensitive to Vancomycin and ciprofloxacin but $100 \%$ resistance to ampicillin. Among the total isolated bacteria $78.4 \%(\mathrm{n}=40 / 51)$ had multidrug resistance. Gram positives and Gram negatives showed an MDR rate of $65 \%(n=13 / 20)$ and $87 \%(\mathrm{n}=27 / 31)$, respectively (Table 4$)$.

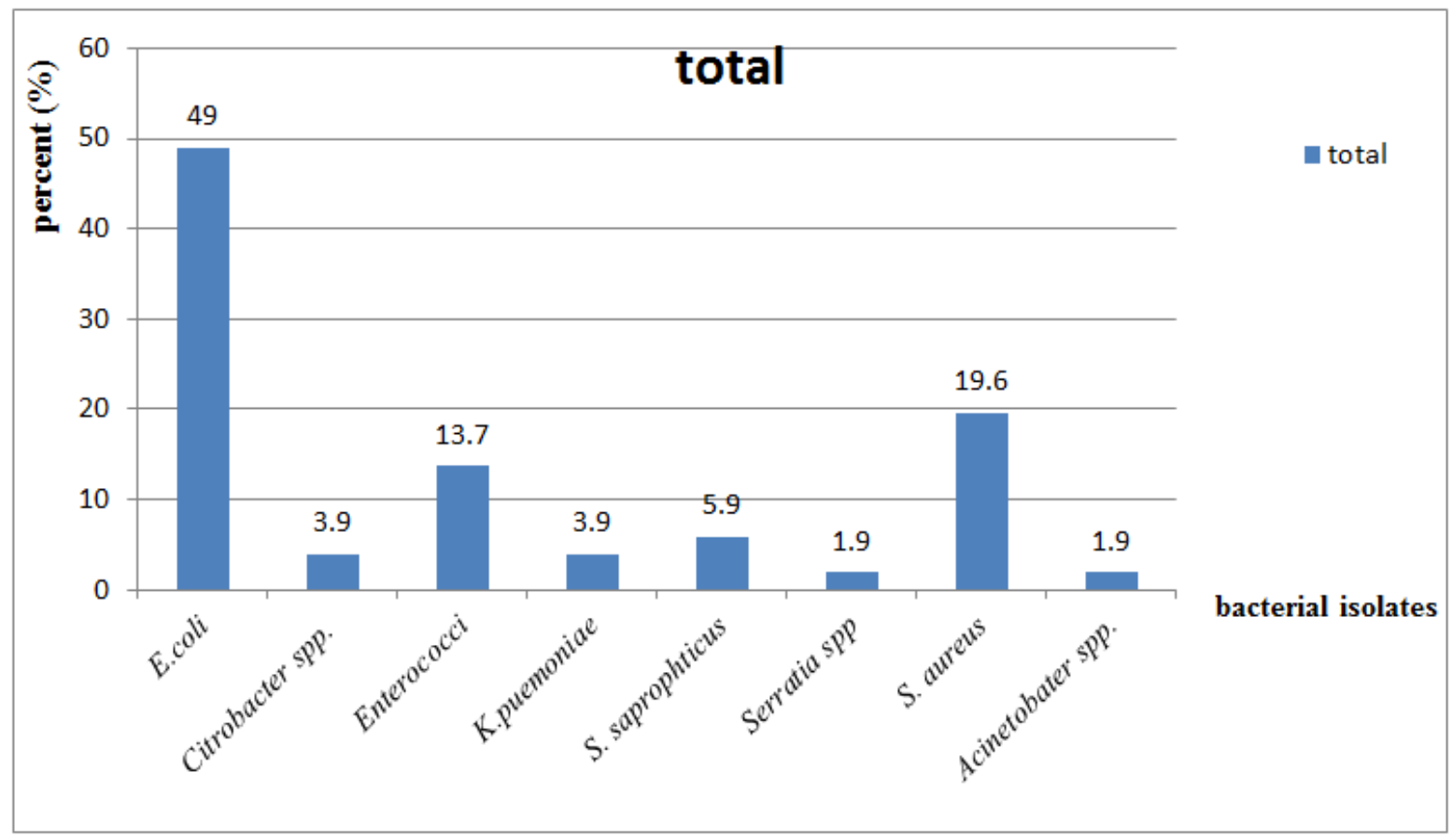

Figure 1: Frequency of bacterial species in cases with significant bacteriuria.

\begin{tabular}{|c|c|c|c|c|c|c|c|c|c|c|c|c|}
\hline Isolated bacteria & Pattern & AMP & AMC & SXT & GN & CPR & CTX & $\mathrm{CPZ}$ & $\mathrm{CRO}$ & $\mathrm{FN}$ & TO & AMK \\
\hline \multicolumn{13}{|l|}{ HAART Naïve } \\
\hline \multirow[t]{2}{*}{ E. coli (3) } & s & $0(0)$ & $0(0)$ & $0(0)$ & $2(66.7)$ & $2(66.7)$ & $3(100)$ & $3(100)$ & $3(100)$ & $3(100)$ & $3(100)$ & $3(100)$ \\
\hline & $\mathrm{R}$ & $3(100)$ & $3(100)$ & $3(100)$ & $1(33.3)$ & $1(33.3)$ & $0(0)$ & $0(0)$ & $0(0)$ & $0(0)$ & $0(0)$ & $0(0)$ \\
\hline \multirow{2}{*}{$\begin{array}{l}\text { K. pneumoniae } \\
\text { (1) }\end{array}$} & $S$ & $0(0)$ & $1(100)$ & $0(0)$ & $1(100)$ & $1(100)$ & $1(100)$ & $1(100)$ & $1(100)$ & $1(100)$ & $1(100)$ & $1(100)$ \\
\hline & $\mathrm{R}$ & $1(100)$ & $0(0)$ & $1(100)$ & $0(0)$ & $0(0)$ & $0(0)$ & $0(0)$ & $0(0)$ & $0(0)$ & $0(0)$ & $0(0)$ \\
\hline \multicolumn{13}{|l|}{ On HAART } \\
\hline \multirow[t]{2}{*}{ E. coli (22) } & S & $3(13.6)$ & $9(40.9)$ & $6(27.3)$ & $22(100)$ & $17(77.3)$ & $18(81.8)$ & $18(81.8)$ & $18(81.8)$ & $21(95.5)$ & $20(90.9)$ & $22(100)$ \\
\hline & $\mathrm{R}$ & $19(86.4)$ & $13(59.1)$ & $16(72.7)$ & $0(0)$ & $5(22.7)$ & $4(18.2)$ & $4(18.2)$ & $4(18.2)$ & $1(4.5)$ & $2(9)$ & $0(0)$ \\
\hline \multirow{2}{*}{$\begin{array}{l}\text { K. } \\
\text { pneumoniae(1) }\end{array}$} & $S$ & $0(0)$ & $0(0)$ & $0(0)$ & $1(100)$ & $0(0)$ & $0(0)$ & $0(0)$ & $0(0)$ & $1(100)$ & $1(100)$ & $1(100)$ \\
\hline & $\mathrm{R}$ & $1(100)$ & $1(100)$ & $1(100)$ & $0(0)$ & $1(100)$ & $1(100)$ & $1(100)$ & $1(100)$ & $0(0)$ & $0(0)$ & $0(0)$ \\
\hline \multirow{2}{*}{$\begin{array}{l}\text { Citrobacter spp. } \\
\text { (2) }\end{array}$} & S & $1(50)$ & $1(50)$ & $1(50)$ & $2(100)$ & $2(100)$ & $2(100)$ & $2(100)$ & $2(100)$ & $2(100)$ & $2(100)$ & $2(100)$ \\
\hline & $\mathrm{R}$ & $1(50)$ & $1(50)$ & $1(50)$ & $0(0)$ & $0(0)$ & $0(0)$ & $0(0)$ & $0(0)$ & $0(0)$ & $0(0)$ & $0(0)$ \\
\hline \multirow[t]{2}{*}{ Serratia (1) } & s & $0(0)$ & $0(0)$ & $0(0)$ & $1(100)$ & $1(100)$ & $1(100)$ & $0(0)$ & $1(100)$ & $1(100)$ & $1(100)$ & $1(100)$ \\
\hline & $\mathrm{R}$ & $1(100)$ & $1(100)$ & $1(100)$ & $0(0)$ & $0(0)$ & $0(0)$ & $1(100)$ & $0(0)$ & $0(0)$ & $0(0)$ & $0(0)$ \\
\hline
\end{tabular}


Citation: Fenta GM, Legese MH, Weldearegay GM (2016) Bacteriuria and their Antibiotic Susceptibility Patterns among People Living with HIV Attending Tikur Anbessa Specialized and Zewditu Memorial Hospital ART Clinics, Addis Ababa, Ethiopia. J Bacteriol Parasitol 7: 292. doi:10.4172/2155-9597.1000292

Page 5 of 7

\begin{tabular}{|l|l|l|l|l|l|l|l|l|l|l|l|l|}
\hline $\begin{array}{l}\text { Acinetobacter } \\
\text { spp. (1) }\end{array}$ & S & NA & NA & $1(100)$ & $1(100)$ & $1(100)$ & NA & NA & NA & NA & $1(100)$ & $1(100)$ \\
\cline { 2 - 12 } & R & NA & NA & $0(0)$ & $0(0)$ & $0(0)$ & NA & NA & NA & NA & $0(0)$ & $0(0)$ \\
\hline
\end{tabular}

NA: Not applicable; AMK: Amikacin; AMP: Ampicillin; AMC: Amoxicillin-Clavulanic acid; SXT: Sulphamethoxazole-trimethoprim; CRO: Ceftriaxone CTX: Cefotaxime; GN: Gentamycin; CPZ: - Ceftazidime; FN: Nitrofurantoin; TO: Tobramycin; CPR: Ciprofloxacillin

Table 2: Antimicrobial susceptibility pattern of Gram-negative bacteria isolated from urine from HIV positive patients.

\begin{tabular}{|c|c|c|c|c|c|c|c|c|c|c|c|c|}
\hline Isolated bacteria & Pattern & P-G & AMP & CXT & AMC & SXT & GN & CPR & CTX & CRO & $\mathrm{NF}$ & VA \\
\hline \multicolumn{13}{|l|}{ HAART Naïve } \\
\hline \multirow{2}{*}{$\begin{array}{l}\text { S. aureus } \\
\text { (2) }\end{array}$} & s & $0(0)$ & $0(0)$ & $2(100)$ & $2(100)$ & $0(0)$ & $2(100)$ & $2(100)$ & $2(100)$ & $2(100)$ & $2(100)$ & NA \\
\hline & $\mathrm{R}$ & $2(100)$ & $2(100)$ & $0(0)$ & $0(0)$ & $2(100)$ & $0(0)$ & $0(0)$ & $0(0)$ & $0(0)$ & $0(0)$ & NA \\
\hline \multirow[t]{2}{*}{ Enterococci (3) } & $S$ & NA & $0(0)$ & NA & NA & NA & NA & $3(100)$ & NA & NA & $3(100)$ & $3(100)$ \\
\hline & $\mathrm{R}$ & NA & $3(100)$ & NA & NA & NA & NA & $0(0)$ & NA & NA & $0(0)$ & $0(0)$ \\
\hline
\end{tabular}

\section{On HAART}

\begin{tabular}{|l|l|l|l|l|l|l|l|l|l|l|l|l|}
\hline \multirow{2}{*}{ S. aureus (8) } & S & $0(0)$ & $0(0)$ & $7(87.5)$ & $7(87.5)$ & $1(12.5)$ & $7(87.5)$ & $5(62.5)$ & $7(87.5)$ & $7(87.5)$ & $8(100)$ & NA \\
\cline { 2 - 12 } & R & $8(100)$ & $8(100)$ & $1(12.5)$ & $1(12.5)$ & $7(87.5)$ & $1(12.5)$ & $3(37.5)$ & $1(12.5)$ & $1(12.5)$ & $0(0)$ & NA \\
\hline \multirow{2}{*}{$\begin{array}{l}\text { S. saprophyticus } \\
\text { (3) }\end{array}$} & S & $0(0)$ & $0(0)$ & $1(33.3)$ & $1(33.3)$ & $1(33.3)$ & $2(66.6)$ & $2(66.6)$ & $3(100)$ & $3(100)$ & $3(100)$ & NA \\
\cline { 2 - 12 } & R & $3(100)$ & $3(100)$ & $2(66.6)$ & $2(66.6)$ & $2(66.6)$ & $1(33.3)$ & $1(33.3)$ & $0(0)$ & $0(0)$ & $0(0)$ & NA \\
\hline \multirow{2}{*}{\begin{tabular}{l} 
Enterococci (4) \\
\cline { 2 - 11 }
\end{tabular}} & S & NA & $0(0)$ & NA & NA & NA & NA & $4(100)$ & NA & NA & $4(100)$ & $4(100)$ \\
\cline { 2 - 12 } & R & NA & $4(100)$ & NA & NA & NA & NA & $0(0)$ & NA & NA & $0(0)$ & $0(0)$ \\
\hline
\end{tabular}

NA: Not applicable; AMP: Ampicillin; AMC--Amoxicillin-Clavulanic acid; SXT-Sulphamethoxazole-trimethoprim; CRO-Ceftriaxone; CTX--Cefotaxime; CPRCiprofloxacillin; GN--Gentamycin; FN-Nitrofurantoin; VA--Vancomycin; CXT: Cefoxitin; P-G: Penicillin G

Table 3: Antimicrobial susceptibility pattern of Gram-positive bacteria isolated from urine from HIV positive patients.

\begin{tabular}{|c|c|c|c|c|c|c|c|c|}
\hline Isolated bacteria & Total $(\%)$ & Ro & R1 & $\mathrm{R} 2$ & R3 & $\mathrm{R} 4$ & $\geq \mathrm{R} 5$ & $\begin{array}{l}\operatorname{MDR}(\geq 2 \text { drug classes)no } \\
(\%)\end{array}$ \\
\hline Gram negative & $31(60.8)$ & $2(6.5)$ & $2(6.5)$ & $8(25.8)$ & $10(32.1)$ & $2(6.5)$ & $7(22.6)$ & $27(87)$ \\
\hline E. coli & $25(80.5)$ & $1(4)$ & $2(8)$ & $7(28)$ & $8(32)$ & $1(4)$ & $6(24)$ & $22(88)$ \\
\hline K. pneumoniae & $2(6.5)$ & $0(0)$ & $0(0)$ & $1(50)$ & $0(0)$ & $0(0)$ & $1(50)$ & $2(100)$ \\
\hline Citrobacter spp & $2(6.5)$ & $1(50)$ & $0(0)$ & $0(0)$ & $1(50)$ & $0(0)$ & $0(0)$ & $1(50)$ \\
\hline Serratia spp & $1(3.2)$ & $0(0)$ & $0(0)$ & $0(0)$ & $1(100)$ & $0(0)$ & $0(0)$ & $1(100)$ \\
\hline Acinetobacter spp & $1(3.2)$ & $0(0)$ & $0(0)$ & $0(0)$ & $0(0)$ & $1(100)$ & $0(0)$ & $1(100)$ \\
\hline Gram positive & $20(39.2)$ & $0(0)$ & $7(35)$ & $0(0)$ & $4(20)$ & $6(30)$ & $3(15)$ & $13(65)$ \\
\hline S. aureus & $10(50)$ & $0(0)$ & $0(0)$ & $0(0)$ & $2(20)$ & $5(50)$ & $3(30)$ & $10(100)$ \\
\hline S. saprophyticus & $3(15)$ & $0(0)$ & $0(0)$ & $0(0)$ & $1(33.3)$ & $1(33.3)$ & $1(33.3)$ & $3(100)$ \\
\hline Enterococcus spp & $7(35)$ & $0(0)$ & $7(100)$ & $0(0)$ & $0(0)$ & $0(0)$ & $0(0)$ & $0(0)$ \\
\hline Total & $51(100)$ & $2(3.9)$ & 9 (17.6) & $8(15.7)$ & $14(27.5)$ & 8 (15.7) & 10 (19.6) & $40(78)$ \\
\hline
\end{tabular}


Citation: Fenta GM, Legese MH, Weldearegay GM (2016) Bacteriuria and their Antibiotic Susceptibility Patterns among People Living with HIV Attending Tikur Anbessa Specialized and Zewditu Memorial Hospital ART Clinics, Addis Ababa, Ethiopia. J Bacteriol Parasitol 7: 292. doi:10.4172/2155-9597.1000292

Page 6 of 7

R0: no antibiotic resistance, R1=resistance to one antibiotic class, R2= resistance to two antibiotic classes, R3= resistance to three antibiotic classes, R4= resistance to four antibiotic classes, $\geq$ R5= resistance to five or more antibiotic classes

Table 4: Multidrug resistance patterns of bacterial isolates from urine from HIV positive individuals.

\section{Discussion}

In our study the overall $11.3 \%(n=51 / 450)$ prevalence of bacteriuria was consistent with previous reports from Ethiopia [11,14]. On the other hand our finding was lower than a study done in Nigeria [15] though it was a higher finding than a study done in Benin City [16]. These differences might be due to methodological differences, study design and included study populations.

We found asymptomatic bacteriuria rate of $7 \%(n=29 / 398)$ which was comparable to findings of other studies in Ethiopia [14]. However a different finding was recorded in studies done from India and Nigeria [5,17]. Rates of bacteriuria were higher in females $13 \%$ $(n=41 / 51)$ than males $7 \%(n=10 / 141)$ similarly with other studies from Ethiopia and other countries $[11,14,18,19]$. This might be due to the anatomy of females (short proximity of the urethra to the anus) that exposed them for a higher risk of UTI compared to males [20,21].

Bacteriuria in our study among HAART $13 \%(\mathrm{n}=42 / 319)$ and HAART naive $7 \%(n=9 / 131)$ participants was similar with other studies done from Ethiopia [11,14]. However, an Indian study reported a higher prevalence of bacteriuria among both HAART and HAART naive participants [22-24]. This difference could be due to lowered CD4 counts among included patients in their study and fits our finding of a higher bacteriuria rate in participants with CD4 counts less than 500 cells $/ \mathrm{mm}^{3}$.

In this study, Gram negative isolates $60.8 \%(\mathrm{n}=31 / 51)$ were more prevalent than gram positive isolates. This finding was comparable with other studies done in Ethiopia; in Gondar [13] and Jimma [10]. In addition it showed similarity with a study from South Africa [8]. This might be due to the presence of unique structure in Gram negative bacteria used for attachments to uroepithelial cells and prevent them from urinary lavage, allowing for multiplication and tissue invasion resulting in invasive infection and pyelonephritis $[25,26]$. In contrary to studies from Calabar, India and Nigeria $[15,25,26]$ where $S$. aureus were the most frequent isolates, Escherichia coli (49\%) were the most frequent isolates in our study which was correlated with other findings in Ethiopia [11,14].

Our findings of Gram negative AST patterns were comparable with other findings from Ethiopia [11,14]. However, it contradicted to a study done in Nigeria [26] where all isolated organisms were highly sensitive to gentamicin, ciprofloxacin, ampicillin and amoxicillinclavulanic acid. This disagreement could be due to variations among antibiotic usage patterns in Nigeria. The findings of our study showed that most Gram positive isolates were sensitive to nitrofurantoin $(100 \%)$, gentamicin $(90 \%)$ and ceftriaxone $(90 \%)$ that was similar to other studies done in different parts of Ethiopia $[11,14]$.

The overall $78 \%$ MDR level $(n=40 / 51)$ was a relatively lower finding as compared to other study done in Ethiopia [27]. Gram positive and Gram negative isolates showed 65\% $(n=13 / 20)$ and $87 \%(n=27 / 31)$ MDR level respectively. These findings were lower findings compared to other studies from Gondar and Bahir Dar, Ethiopia [14,27]. However, our findings were higher than study findings from Dessie, Ethiopia [28].

\section{Conclusion}

Bacteriuria was common among HAART users compared with HAART naïve. Participants with low CD4 counts were more frequently infected with bacterial urinary pathogens compared with who had higher CD4 counts. More than three quarters of all isolated bacteria were resistant to two or more commonly prescribed antimicrobial drugs. Thus, regular monitoring of bacteriuria and their antimicrobial susceptibility patterns among this group of individuals is recommended.

\section{Acknowledgment}

We greatly appreciate Addis Ababa University for supporting this study. We are also grateful to the Department of Clinical Laboratory Sciences to give us ethical clearance for this study. Our deep gratitude goes to those study participants gave us their willingness to participate in this study by giving written consent form. Furthermore, we also wish to acknowledge $\mathrm{Mr}$ Solomon Ali (Jimma University. Microbiologist) and DrØystein Haarklau Johansen (Consultant clinical microbiologist, MD DTM \& H) for their invaluable suggestion and language editing.

\section{References}

1. Alka N, Priti S, Shanta SN (2012) Bacterial pathogens in urinary tract infection and antibiotic susceptibility pattern. J Phar Bioth Sci 21: 1-3.

2. Rashmi KS, RaviKumar KL, Bhagyashree HN (2013) Asymptomatic bacteriuria in HIV/AIDS Patients: Occurrence and risk associated with low CD4 counts. J Evolution Med Dent Sci 2: 3358-66.

3. De Pinho AM, Lopes GS, Rames-Filho CS, Santos OR, De Oliveria MP, et al. (1994) Urinary tract infection in men with AIDS. Genitourin Med 70: 30-4.

4. Heyns CF, Smit SG, Merwe AD, Zarrabi AD (2013) Urologic aspects of HIV \& AIDS. Nature Reviews Urology 10: 713-22.

5. Evans JK, Mc Owan A, Hilman RJ, Foster GE (1995) Incidence of symptomatic urinary tract infections in HIV seropositive patients and the use of cotrimoxazole as prophylaxis against Pneumocystis carinii pneumonia. Genitourin Med 71: 120-22.

6. Komala M, Sampath K (2013) Urinary Tract Infection: Causes, Symptoms, Diagnosis and it's Management. Indian J research Pharm Biotech 1: 226-29.

7. World Health Organization (2014) Antimicrobial Resistance. Global Report on Surveillance. Geneva. .

8. Jordi V, Tibor P (2010) Update on Antibacterial Resistance in LowIncome Countries: Factors Favoring the Emergence of Resistance. The Open Inf Dis J 4: 38-54.

9. Iweriebor BC, Obi CL, Akinyemi O (2012) Uropathogens isolated from HIV-infected patients from Limpopo province, South Africa. Afr J Biotechnol 11: 10598-10604.

10. Biradar SK, Doddamani PK (2013) Prevalence and antibiogram of uropathogens in a tertiary care hospital. World J. Pharmaceut Res 2: 1534-1543.

11. Debalke S, Cheneke W, Tassew H, Awol M (2014) Urinary Tract Infection among Antiretroviral Therapy Users and Nonusers in Jimma University Specialized Hospital, Jimma, Ethiopia. Int J Microbio 2014: 1-6. 
Citation: Fenta GM, Legese MH, Weldearegay GM (2016) Bacteriuria and their Antibiotic Susceptibility Patterns among People Living with HIV Attending Tikur Anbessa Specialized and Zewditu Memorial Hospital ART Clinics, Addis Ababa, Ethiopia. J Bacteriol Parasitol 7: 292. doi:10.4172/2155-9597.1000292

Page 7 of 7

12. Chees BM (2006) Biochemical testes to identify bacteria: district laboratory practice in tropical countries 2: 50-55.

13. Clinical and Laboratory Standards Institute (CLSI) (2014) Performance Standards for Antimicrobial Disk Susceptibility Tests; Twenty-Second Informational Supplement. CLIS 34: M100-S24.

14. Alemu A, Dagnew M, Alem M, Gizachew M (2013) Uropathogenic Bacterial Isolates and their Antimicrobial Susceptibility Patterns among HIV/AIDS Patients Attending Gondar University Specialized Hospita Gondar. Northwest Ethiopia. J Microbiol Res Rev 1: 42-51.

15. Inyang-Etoh PC, Udofia GC, Alaribe AA, Udonwa NE (2009) Asymptomatic Bacteriuria in Patients on Antiretroviral Drug Therapy in Calabar. J Med Sci 9: 270-75.

16. Ibadin O, Michael P, Onunu A, Ukoh G (2006) Urinary Tract Infection in Adolescent/Young Adult Nigerians with Acquired Human Immuno Deficiency Disease in Benin City. A Peer-review J Biomed Sci 5: 55-60.

17. Akinsegun A, Ibidun BS, Sarah A, Olajumoke O, Adewumi A, et al (2013) Prevalence of Asymptomatic Bacteriuria in HIV Infected Patients in a Tertiary Hospital in Lagos, Nigeria. World J AIDS 3: 105-110.

18. Samuel SO, Salami TAT, Adewuyi GM, Babatope E, Ekozien M (2012) Prevalence of Urinary Tract Infections among a cohort of HIV Positive Patients accessing care in a rural health centre in Nigeria. J Microbio Biotech Res 2: 507-510.

19. Girum F, Ameha K, Genene T (2015) Identification of E. coli from patients of urinary tract infection and its resistance in Dil-Chora hospital, Dire Dawa, Ethiopia. Int J Microbio Immunol Res 4: 015-020.
20. Najar MS, Saldanha CL, Bandy KA (2009) Approach to urinary tract infection. Indian J Nephrol 19: 129-39.

21. Mwaka AD, Mayanjia-Kizza H, Kigonya E, Kaddu-Mulindwa D (2011) Bacteriuria among adult non-pregnant women attending Mulago hospital assessment center in Uganda. Afri Health Sci 11: 182-89.

22. Murugesh K, Deepa S, Ravindranath C, Venkatesha D (2014) Multi Drug Resistant Uropathogens in HIV: Are They A Threat to Community? Int J Sci Stu 2: 38-40

23. Lebovitch S, Mydlo JH (2008) HIV-AIDS: Urologic Considerations. Urol Clin North Am 35: 59-68.

24. Pradip B, Kalyan D, Bedabindu S (2013) Spectrum of opportunistic infections among HIV/AIDS patients of Tripura. J Indian Acad Clin Med 14: 218-21.

25. Silvio A (2015) Urinary Tract Infections: how it happens? EMJ Urol 3: 62-67.

26. Ifeanyichukwu I, Emmanuel N, Chika E, Anthonia O, Esther UI, et al (2013) Frequency and antibiogram of uropathogens isolated from urine samples of HIV infected patients on ART. Am J Biosci 1: 50-53.

27. Fantahun B, Bayeh A (2009) Antimicrobial resistance of bacterial isolates from urinary tract infections at Felge Hiwot Ref Hosp Ethiopia. Ethiop J Health Dev 23: 236-38.

28. Kibret M, Abera B (2014) Prevalence and antibiogram of bacterial isolates from urinary tract infections at Dessie Health Research Laboratory, Ethiopia. Asian Pac J Trop Biomed 4: 164-168. 